\title{
HOXA9 Expression is Associated with Advanced Tumour Stage and Prognosis in Nasopharyngeal Carcinoma
}

\author{
Tiancong Liu' \\ Chao $\mathrm{Ji}^{2}$ \\ Yang Sun' \\ Weiliang Bai' \\ 'Department of Otorhinolaryngology- \\ Head and Neck Surgery, Shengjing \\ Hospital, China Medical University, \\ Shenyang, People's Republic of China; \\ ${ }^{2}$ Department of Clinical Epidemiology, \\ Shengjing Hospital, China Medical \\ University, Shenyang, People's Republic of \\ China
}

Background: Homeobox A9 (HOXA9), a member of the HOX protein family, plays diverse biological roles in embryonic development and carcinogenesis. The prognostic value of HOXA9 expression in nasopharyngeal carcinoma (NPC) is not well-defined. The present study aimed to analyse NPC tissue HOXA9 expression and determine prognostic significance by investigating the relationship between HOXA9 expression and clinicopathologic features.

Methods: Between January 2010 and December 2014, 252 NPC patients and 30 chronic nasopharyngitis patients (control group) were recruited to participate in the present study. Correlations between HOXA9 expression level and clinicopathologic features (including survival) were analysed.

Results: High HOXA9 expression was significantly associated with clinical stage $(p<0.01)$ and higher T stage $(p<0.01)$. In univariate analysis, high HOXA9 expression predicted overall survival (OS) $(p=0.011)$. In multivariate analysis, HOXA9 over-expression independently and significantly predicted poorer PFS $(p<0.01$, hazard ratio $(\mathrm{HR})=2.387,95 \%$ CI $[0.876,6.545])$ and $\mathrm{OS}(p<0.01, \mathrm{HR}=2.486,95 \%$ CI $[1.041,8.926])$.

Conclusion: High HOXA9 expression is an independent prognostic factor associated with advanced tumour stage and poorer survival in NPC patients.

Keywords: HOXA9, nasopharyngeal carcinoma, NPC, prognosis

\section{Introduction}

Nasopharyngeal carcinoma (NPC) is a malignant neoplasm with a characteristic geographic distribution and a high incidence. ${ }^{1,2}$ Significant advances in early-stage treatment strategies have resulted in good therapeutic outcomes, including a high five-year survival rate of up to $85 \%$. However, a subset of advanced-stage cancers exhibit chemo- and/or radio-resistance, resulting in local recurrence or distant metastasis. $^{3,4}$ Therefore, early diagnosis or novel approaches to more advanced tumour stages are critical and urgent challenges to ensure optimal outcomes. ${ }^{5}$ Identification of specific biomarkers reflecting emergence and progression of NPC will improve diagnosis, prognostication, and therapeutic intervention and monitoring, thereby contributing to enhanced patient quality of life and survival.

The homeobox $(H O X)$ gene was first discovered in relation to developmental regulation of Drosophila. Mammals possess 39 HOX genes, divided into four clusters (A, B, C, and D) which are evenly distributed across chromosomes 7, 17, 12, and 2. Each cluster contains between nine and 13 gene loci, which are regulated
Correspondence: Weiliang Bai Shengjing Hospital, China Medical University, 36 Sanhao Street, Heping

District, Shenyang, Liaoning, I 10004 ,

People's Republic of China

Email bweiliangcmu@163.com 
by highly conserved transcription factors; stringent control is essential given that these genes represent major regulators of embryonic development and cell differentiation. ${ }^{6,7}$ A member of the HOX gene family, HOXA9 has recently been demonstrated to exhibit increased expression in a variety of human malignant tumours (including acute myeloid leukaemia (AML), ${ }^{8}$ colorectal cancer (CRC), ${ }^{9}$ malignant glioma, ${ }^{10}$ lung cancer, ${ }^{11}$ and is closely associated with tumour progression, invasion, metastasis, and prognosis.

To the best of our knowledge, HOXA9 expression has never before been evaluated in a well-defined NPC cohort. Therefore, the present study aimed to determine HOXA9 expression level and evaluate its clinical significance in NPC patients.

\section{Materials and Methods}

\section{Patients and Tissue Specimens}

Patients undergoing biopsy at the Shengjing Hospital of China Medical University between January 2010 and December 2014 were screened, and 252 NPC patients as well as 30 chronic nasopharyngitis patients (control group) were recruited. Exclusion criteria included early-stage (stage I) NPC (which generally carries a good prognosis) and prior NPC treatment. All study protocols were approved by the Ethical Committee of Shengjing Hospital, written consent about the purpose of the study was obtained from all participants, and the study proceeded in accordance with the principles of the Declaration of Helsinki (2013). All participants were hospitalized for biopsy, and study involvement did not alter the standard of routine care.

Complete clinical and follow-up data were recorded for all participants. Clinical staging was performed according to the AJCC/UICC staging system (7th edition). Biopsy specimens (252 NPC and 30 chronic nasopharyngitis) were collected and were flash-frozen in liquid nitrogen prior to preparation and analysis. Specifically, only 178 of the 252 patients with nasopharyngeal carcinoma were tested for EBV-serology.

\section{Tumour Histological Subtype Classification and Immunohistochemistry} For histology, specimens were prepared as follows. Tumours were then subtype-classified according to the 2005 WHO histological classification system for tumours of the nasopharynx. For immunohistochemistry, NPC and control group specimens were embedded in paraffin and cut into $4 \mu \mathrm{m}$ thick sections, as previously described. ${ }^{12}$ For antigen retrieval, sections were deparaffinised and dehydrated, incubated with $3 \% \mathrm{H}_{2} \mathrm{O}_{2}$ for 10 min, rinsed twice in distilled water, and microwaved for $8 \mathrm{~min}$. Sections were then incubated overnight with anti-HOXA9 primary antibody (1:200) (Absin Bioscience Inc., Shanghai, China; abs136206; polyclonal rabbit anti-human) or PBS (negative control) at $4{ }^{\circ} \mathrm{C}$. After rinsing in PBS, sections were incubated for $2 \mathrm{~h}$ with biotinylated secondary antibodies (1:1000) (Absin Bioscience Inc., Shanghai, China; abs998$5 \mathrm{~mL}$; polyclonal mouse anti-rabbit $\mathrm{IgG}$ ). After rinsing in PBS, addition of the chromogen 3,3'-diaminobenzidine facilitated visualization of HOXA9. Sections were weakly counterstained with haematoxylin and slide-mounted, as previously described. ${ }^{12}$

\section{Image Acquisition and Analysis}

Slides were evaluated using a light microscope (E400; Nikon, Tokyo, Japan) (400x magnification). Five visual fields per section were photographed. Representative images were analysed using Image-Pro Plus version 6.0 (Meyer Instruments Inc., Houston, USA). Briefly, positive relative integral optical density (IOD) and tissue area measurement (pixel area) were obtained via line segmentation of each image. Expression level of HOXA9 was compared between NPC and control group specimens. Average optical density ( $\mathrm{AO}=\mathrm{IOS} /$ pixel area) was calculated for the five fields of each specimen, and the median AO across all specimens was used as the cut-off value to classify specimens/patients into high or low HOXA9 expression groups.

\section{Determining HOXA9 Expression Prognostic Value}

Two parameters were used to assess prognostic value: disease-free survival (DFS; interval to first recurrence at any site) and overall survival (OS; interval to death from any cause). Kaplan-Meier survival curves were constructed, and survival intervals of high versus low HOXA9 expression NPC patient groups were compared using the Log rank test. In addition, potential correlations between HOXA9 expression level and other clinicopathologic features (age, gender, clinical stage, T stage, $\mathrm{N}$ stage, and histological grade) were investigated by means of Pearson correlation analysis. Finally, association of OS with HOXA9 expression level and the above 
clinicopathologic features was evaluated via univariate followed by multivariate Cox regression analysis in order to determine which factors have independent prognostic utility.

\section{Statistical Analysis}

The statistical significances of differences between HOXA9 expression and various clincopathological parameters were evaluated by Chi-square test. The endpoints for outcome measurement including DFS and OS were calculated by the Kaplan-Meier method and analyzed by the Log rank test. Multivariate analysis was performed by using the Cox proportional hazards model. All tests are two-sided, and $\mathrm{P}$ values less than 0.05 were considered statistically significant. Data analysis was performed using SPSS ver. 12 software.

\section{Results}

\section{Patient Demographic and Clinical Data}

A total of 252 NPC patients with a median age of 51 (range 22-78) were enrolled. The majority (183/252; $72.6 \%$ ) of participants were male. Regarding staging, 37 participants (14.7\%) were classified as stage II, 119 participants (47.2\%) were classified as stage III, 60 participants $(23.8 \%)$ were classified as stage $\mathrm{IV}_{\mathrm{a}}$, and 36 participants $(14.3 \%)$ were classified as stage $\mathrm{IV}_{\mathrm{b}}$. At the time of study completion, 96 participants $(38.1 \%)$ were no longer surviving, with death attributed to various causes, including tumour progression, recurrence, metastasis, and causes unrelated to cancer. Clinical features, pathological data and HOXA9 expression in nasopharyngeal carcinoma tissues and non-tumoral tissues are summarized in Tables 1 and 2 .

\section{Expression Patterns of HOXA9 as Detected by Immunohistochemistry}

Staining was largely observed distributed throughout the nucleus and cytoplasm (Figure 1: yellow-brown granules). Relative to control group tissues, NPC tissues exhibited significantly higher HOXA9 expression $(p<0.05)$ (Table $3)$. Of 252 NPC patients, 127 (50.4\%) were classified as exhibiting high levels of HOXA9 expression (Figure 1C), while 125 (49.6\%) were classified as exhibiting low levels of HOXA9 expression (Figure 1B), based on a median AO value of $4.98 \times 10^{-3}$. Of 30 chronic nasopharyngitis patients, only a single patient (3.3\%) was classified as exhibiting high levels of HOXA9 expression (Figure 1A).
Table I Patients Demographics and Disease Characteristics

\begin{tabular}{|c|c|c|c|}
\hline \multirow[t]{2}{*}{ Characteristics } & & \multicolumn{2}{|c|}{$N=252$} \\
\hline & & Cases & $\begin{array}{c}\text { Percentage } \\
\text { (\%) }\end{array}$ \\
\hline \multirow[t]{5}{*}{ Age (years) } & & & \\
\hline & Median & 51 & \\
\hline & Range & $22-78$ & \\
\hline & $\leq 50$ & 132 & 52.4 \\
\hline & $>50$ & 120 & 47.6 \\
\hline \multirow[t]{3}{*}{ Gender } & & & \\
\hline & Male & 183 & 72.6 \\
\hline & Female & 69 & 27.4 \\
\hline \multirow{4}{*}{$\begin{array}{l}\text { Histological } \\
\text { grade }\end{array}$} & & & \\
\hline & Keratinizing & 53 & 21.0 \\
\hline & +Non-keratinizing & & \\
\hline & Undifferentiated & 199 & 79.0 \\
\hline \multirow{3}{*}{$\begin{array}{l}\text { Primary tumor } \\
\text { (T) }\end{array}$} & & & \\
\hline & & 105 & \\
\hline & $\mathrm{T}_{3}+\mathrm{T}_{4}$ & 147 & 58.3 \\
\hline \multirow{3}{*}{$\begin{array}{l}\text { Nodule status } \\
\text { (N) }\end{array}$} & & & \\
\hline & $\mathrm{N}+\mathrm{N}$ & 89 & 35.3 \\
\hline & $\mathrm{N}_{2}+\mathrm{N}_{3}$ & 163 & 64.7 \\
\hline \multirow[t]{5}{*}{ Stage } & & & \\
\hline & II & 37 & 14.6 \\
\hline & III & 119 & 47.2 \\
\hline & $\mathrm{IV}_{\mathrm{a}}$ & 60 & 23.8 \\
\hline & $\mathrm{IV}_{\mathrm{b}}$ & 36 & 14.3 \\
\hline \multirow[t]{3}{*}{ Treatment } & Radiotherapy & 240 & 95.2 \\
\hline & +Chemotherapy & & \\
\hline & Radiotherapy & 12 & 4.8 \\
\hline \multirow[t]{6}{*}{ Patient status } & & & \\
\hline & Tumor relapse & 31 & 12.3 \\
\hline & Metastasis & 75 & 29.8 \\
\hline & Overall survival & 156 & 62.0 \\
\hline & Disease free survival & 114 & 45.3 \\
\hline & Death & 96 & 38.1 \\
\hline
\end{tabular}

\section{Prognostic Utility of HOXA9 Expression}

Expression level of HOXA9 correlated with only two clinicopathologic features (Table 2): high HOXA9 expression correlated positively and significantly with NPC clinical stage $(p<0.01)$ and T stage $(p<0.01)$.Of 252 patients with nasopharyngeal cancer, only 178 had EBV serological testing. A positive result indicates 
Table 2 The Relationship Between the Expression of HOXA9 and Clinical Pathological Characteristics of Nasopharyngeal Carcinoma

\begin{tabular}{|c|c|c|c|c|c|c|}
\hline Parameters & $\begin{array}{c}\text { No. } \\
\text { of Case }\end{array}$ & Average Opticle $\left(\times 10^{-3}\right)$ & $\begin{array}{c}\text { High } \\
\text { Expression }\end{array}$ & $\begin{array}{c}\text { Low } \\
\text { Expression }\end{array}$ & $\chi^{2}$ & $P$ value \\
\hline $\begin{array}{l}\text { Gender } \\
\text { Male } \\
\text { Female }\end{array}$ & $\begin{array}{l}183 \\
69\end{array}$ & $\begin{array}{l}4.96(0.27-21.24) \\
3.24(1.12-18.70)\end{array}$ & $\begin{array}{l}96 \\
31\end{array}$ & $\begin{array}{l}87 \\
38\end{array}$ & 1.13 & 0.286 \\
\hline $\begin{array}{l}\text { Age (years) } \\
\quad \leq 50 \\
>50\end{array}$ & $\begin{array}{l}132 \\
120\end{array}$ & $\begin{array}{l}4.79(1.26-2 \mid .24) \\
4.62(0.27-20.70)\end{array}$ & $\begin{array}{l}63 \\
64\end{array}$ & $\begin{array}{l}69 \\
56\end{array}$ & 0.79 & 0.374 \\
\hline $\begin{array}{l}\text { Histological grade } \\
\text { Keratinizing } \\
+ \text { Non-keratinizing } \\
\text { Undifferentiated }\end{array}$ & $\begin{array}{l}53 \\
199\end{array}$ & $\begin{array}{l}4.34(0.27-19.87) \\
4.15(0.33-21.24)\end{array}$ & $\begin{array}{l}28 \\
99\end{array}$ & $\begin{array}{l}25 \\
100\end{array}$ & 0.16 & 0.690 \\
\hline $\begin{array}{l}\text { Primary tumor }(\mathrm{T}) \\
\qquad \mathrm{T}_{1}+\mathrm{T}_{2} \\
\mathrm{~T}_{3}+\mathrm{T}_{4}\end{array}$ & $\begin{array}{l}105 \\
147\end{array}$ & $\begin{array}{l}2.69(0.27-2 । .24) \\
6.72(0.98-21.05)\end{array}$ & $\begin{array}{c}18 \\
109\end{array}$ & $\begin{array}{l}87 \\
38\end{array}$ & 79.62 & $<0.01 *$ \\
\hline $\begin{array}{l}\text { Nodule status }(\mathrm{N}) \\
\qquad \begin{array}{l}\mathrm{N}_{0}+\mathrm{N}_{1} \\
\mathrm{~N}_{2}+\mathrm{N}_{3}\end{array}\end{array}$ & $\begin{array}{c}89 \\
163\end{array}$ & $\begin{array}{l}3.48(0.27-13.80) \\
4.78(0.35-21.24)\end{array}$ & $\begin{array}{l}52 \\
75\end{array}$ & $\begin{array}{l}37 \\
88\end{array}$ & 3.549 & 0.060 \\
\hline $\begin{array}{l}\text { Stage } \\
\text { II } \\
\text { III } \\
\mathrm{IV}_{\mathrm{a}} \\
\mathrm{IV}_{\mathrm{b}}\end{array}$ & $\begin{array}{c}37 \\
119 \\
60 \\
36\end{array}$ & $\begin{array}{c}\text { I. } 48(0.27-7.89) \\
3.38(0.58-\mid 7.89) \\
7.24(1.78-15.87) \\
10.76(4.78-21.24)\end{array}$ & $\begin{array}{c}6 \\
53 \\
45 \\
23\end{array}$ & $\begin{array}{l}31 \\
66 \\
15 \\
13\end{array}$ & 36.08 & $<0.01 *$ \\
\hline
\end{tabular}

Note: *Statistically significant.

Epstein-Barr virus infection. There was no significant correlation between HOXA9 positive expression and Epstein-Barr virus infection in patients with nasopharyngeal carcinoma $(p>0.05)$ (Table 4$)$. The relationship between up-regulation of HOXA9 protein expression and prognosis of patients with NPC was analyzed. Kaplan-Meier survival curves are shown in Figure 2, and the differences in survival time of patients with
NPC were compared by Log rank test. Among the 252 study patients, the patients with high levels of HOXA9 expression experienced significantly poorer outcomes in terms of PFS $(\mathrm{P}<0.0001)$ and OS $(\mathrm{P}=0.0015)$ in comparison with patients low levels of HOXA9 expression (Figure 2). This indicates that patients in the high HOXA9 expression group experienced significantly poorer outcome in terms of DFS and OS.
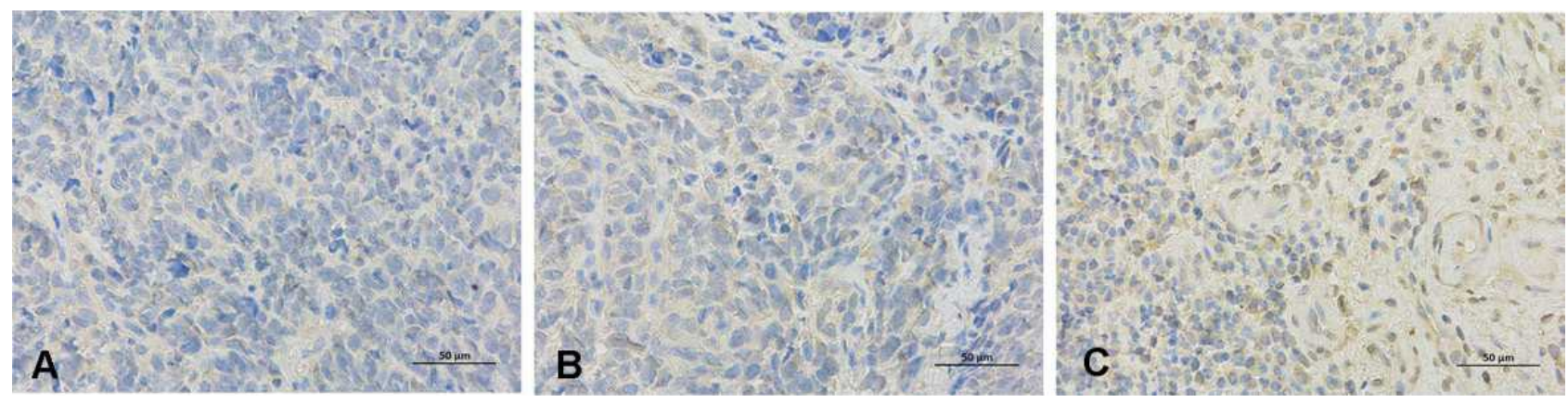

Figure I Immunohistochemical staining for expression of HOXA9 in nasopharyngeal carcinoma (NPC) and mucosal tissue of chronic nasopharyngitis (SP×400). (A) low HOXA9 expression in mucosal tissue of chronic nasopharyngitis. (B) low HOXA9 expression in NPC tissue. (C) high HOXA9 expression in NPC tissue. 
Table 3 Expression of HOXA9 in Nasopharyngeal Carcinoma and Chronic Nasopharyngitis

\begin{tabular}{|l|c|c|c|c|c|}
\hline Group & No. of Case & Average Opticle $\left(\times 10^{-3}\right)$ & $\begin{array}{c}\text { High } \\
\text { Expression }\end{array}$ & $\begin{array}{c}\text { Low value } \\
\text { Expression }\end{array}$ \\
\hline NPC group & 252 & $4.98(0.27-21.24)$ & 127 & 125 & $0.001 *$ \\
\hline Chronic nasopharyngitis & 30 & $0.98(0.18-6.74)$ & 1 & 29 \\
\hline
\end{tabular}

Note: *Statistically significant.

Table 4 Correlation of HOXA9 Expression in Nasopharyngeal Carcinoma with EB Virus Infection

\begin{tabular}{|l|c|c|c|c|c|}
\hline \multirow{2}{*}{$\begin{array}{l}\text { EBV- } \\
\text { Serology }\end{array}$} & $\begin{array}{c}\text { No. of } \\
\text { Cases }\end{array}$ & \multicolumn{2}{|c|}{$\begin{array}{c}\text { HOXA9 } \\
\text { Expression }\end{array}$} & \multirow{2}{*}{ P value } & \\
\cline { 3 - 4 } & & High & Low & & \\
\hline Positive & 98 & 51 & 47 & 0.191 & 0.662 \\
\hline Negative & 80 & 39 & 41 & & \\
\hline
\end{tabular}

In univariate analysis, T stage and HOXA9 expression level were significantly associated with prognosis (OS interval) $(p<0.05)$ (Table 5). In multivariate analysis, HOXA9 over-expression independently and significantly predicted poorer PFS $(p<0.01$, hazard ratio $(\mathrm{HR})=2.387$, $95 \%$ CI $[0.876,6.545])$ and $\mathrm{OS}(p<0.01, \mathrm{HR}=2.486$, 95\% CI $[1.041,8.926]$ ) (Table 6). This indicates that $\mathrm{T}$ stage and HOXA9 expression independently predict a poorer prognosis in NPC patients.

\section{Discussion}

Evidence is mounting that transcription factor-mediated regulation of gene expression plays an important role in the emergence and progression of neoplasia. ${ }^{13}$ The HOX genes encode transcription factors that regulate cell selfrenewal and differentiation. ${ }^{14}$ Specifically, the product of family member HOXA9 is an important transcriptional regulator with key roles in controlling embryonic development and cell differentiation.

As mentioned above, recent studies demonstrate abnormal HOXA9 expression in human AML, ${ }^{9}$ colorectal cancer, ${ }^{10}$ malignant glioma, ${ }^{11}$ lung cancer, ${ }^{12}$ and other tumours. This protein plays an important role in tumour progression (including metastasis), and is closely associated with prognosis. For example, HOXA9 levels are 2-8 times higher than normal in over $50 \%$ of AML patients, and HOXA9 demonstrated prognostic utility both alone and in combination with other upstream and downstream molecules. ${ }^{15}$ Consistent with these findings, HOXA9 mRNA levels were elevated in AML patients undergoing initial treatment or during recurrence, and were associated with tumour load, prognosis, and treatment efficacy. ${ }^{16}$ In malignant glioma patients, HOXA9 expression levels are similarly significantly elevated and are closely associated with prognosis ${ }^{17}$ high HOXA9 expression is associated with a significantly shorter OS

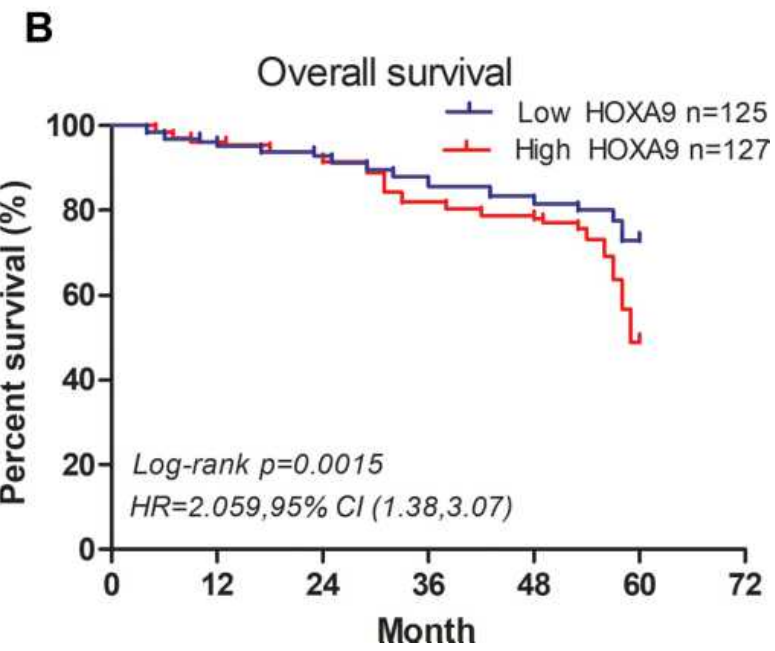

Figure 2 Kaplan-Meier survival curves for nasopharyngeal carcinoma patients exhibiting low versus high HOXA9 expression. (A) Progress free survival. (B) Overall survival. $P$ value were obtained using the Log rank test. 
Table 5 Cox Risk Regression Model for Single Factor Analysis of Factors Affecting the Prognosis of Patients with Nasopharyngeal Carcinoma

\begin{tabular}{|c|c|c|}
\hline Parameters & HR $(95 \% \mathrm{Cl})$ & $P$ value \\
\hline Gender (Female vs Male) & $\begin{array}{c}1.36 \\
(0.91-2.03)\end{array}$ & 0.511 \\
\hline Age ( $>50$ years vs $\leq 50$ years) & $\begin{array}{c}2.34 \\
(0.89-6.19)\end{array}$ & 0.135 \\
\hline $\begin{array}{l}\text { Histological grade } \\
\text { (Keratinizing+Non-keratinizing vs } \\
\text { Undifferentiated) }\end{array}$ & $\begin{array}{c}1.16 \\
(0.49-2.7 I)\end{array}$ & 0.143 \\
\hline Primary tumor $\left(T_{1}+T_{2}\right.$ vs $\left.T_{3}+T_{4}\right)$ & $\begin{array}{c}7.63 \\
(2.83-20.57)\end{array}$ & $0.013 *$ \\
\hline Nodule status $\left(\mathrm{N}_{0}+\mathrm{N}_{1}\right.$ vs $\left.\mathrm{N}_{2}+\mathrm{N}_{3}\right)$ & $\begin{array}{c}2.52 \\
(0.91-7.02)\end{array}$ & 0.083 \\
\hline Stage (II vs III+IV) & $\begin{array}{c}1.12 \\
(0.42-3.02)\end{array}$ & 0.432 \\
\hline HOXA9 expression (High vs Low) & $\begin{array}{c}2.30 \\
(1.06-4.99)\end{array}$ & $0.011 *$ \\
\hline
\end{tabular}

Note: *Statistically significant.

Abbreviations: $\mathrm{HR}$, hazard ratio; $\mathrm{Cl}$, confidence interval.

interval. In addition, HOXA9 expression level correlates positively with glioma stage, which may suggest its involvement in promoting tumour progression. ${ }^{18}$ In colon cancer, too, abnormal HOXA9 expression is associated with TNM stage, lymph node metastasis, histological grade, and prognosis. ${ }^{19}$ Expression of HOXA9 is elevated in CRC tissue and is closely associated with metastatic potential, histological grade, TNM stage, and a poorer prognosis. ${ }^{20}$ Finally, HOXA9 expression is also elevated in lung cancer tissue, and such over-expression is associated with lymph node metastasis.

However, to the best of our knowledge, HOXA9 expression in NPC has not yet been investigated, and its potential roles in this cancer type remain to be defined. Therefore, the present study compared HOXA9 expression levels between NPC and chronic nasopharyngitis tissues using immunohistochemistry, and investigated HOXA9 expression level clinical significance by comparing clinicopathologic features and survival outcomes of NPC patients exhibiting high and low HOXA9 expression levels. In all tissue specimens, HOXA9 was detected mainly in the cytoplasm and nucleus, and expression level was significantly higher in NPC than in chronic nasopharyngitis tissues. Statistical analysis confirmed that HOXA9 expression level correlated positively and significantly with clinical stage and $\mathrm{T}$ stage, suggesting an association with tumour progression. In addition, prognosis (in terms of PFS and OS) was significantly poorer in patients exhibiting high levels of HOXA9 expression, and multivariate analysis demonstrated that HOXA9 expression is an independent risk factor for poorer NPC prognosis.

Indeed, recent studies demonstrate that HOXA9 is not only closely associated with clinicopathologic characteristics, therapeutic efficacy, and prognosis, but may also regulate tumour stem cell proliferation and apoptosis, invasion and metastasis, drug resistance, and selfrenewal. $^{21,22}$ In colon cancer stem cells, HOXA9 overexpression promoted self-renewal and proliferation, and all-trans retinoic acid-induced repression of HOXA9 expression exerted an anti-neoplastic effect. Interestingly, HOXA9 expression is also higher in 5-fluorouracil- and oxaliplatin-resistant CRC cells than in treatment-susceptible cells. Drug resistance often leads to treatment failure, resulting in tumour progression and a significantly poorer prognosis. ${ }^{23}$ The association between abnormal HOXA9 expression and drug resistance suggests potential novel research avenues for overcoming drug resistance. ${ }^{24}$

Table 6 Cox Risk Regression Model for Multivariate Survival Analysis of Factors Affecting the Prognosis of Patients with Nasopharyngeal Carcinoma

\begin{tabular}{|c|c|c|c|c|c|c|c|}
\hline \multirow[t]{2}{*}{ Parameter } & \multirow[t]{2}{*}{ Category } & \multicolumn{3}{|c|}{ PFS } & \multicolumn{3}{|c|}{ os } \\
\hline & & HR & $95 \% \mathrm{Cl}$ & $P$ value & HR & $95 \% \mathrm{Cl}$ & $P$ value \\
\hline Primary tumor(T) & $\begin{array}{l}T_{1}-T_{2} \\
T_{3}-T_{4}\end{array}$ & $\begin{array}{c}1 \\
1.838\end{array}$ & $\begin{array}{c}- \\
0.978-3.543\end{array}$ & $0.022 *$ & $\begin{array}{c}1 \\
2.732\end{array}$ & $\begin{array}{c}- \\
0.967-6.202\end{array}$ & $0.032 *$ \\
\hline HOXA9 expression & $\begin{array}{l}\text { Low expression } \\
\text { High expression }\end{array}$ & $\begin{array}{c}1 \\
2.387\end{array}$ & $\begin{array}{c}- \\
0.876-6.545\end{array}$ & $<0.01 *$ & $\begin{array}{c}1 \\
2.486\end{array}$ & $\begin{array}{c}- \\
1.04 \mid-8.926\end{array}$ & $<0.01 *$ \\
\hline
\end{tabular}

Notes: *Statistically significant.

Abbreviations: $\mathrm{HR}$, hazard ratio; $\mathrm{Cl}$, confidence interval; PFS, progression free survival; OS, overall survival. 
More recent investigations have discovered that HOXA9 can act as both an oncogene and a tumour suppressor gene in a context-dependent manner. ${ }^{25}$ The literature has shown that the expression of HOX genes may be increased or decreased in different tumors and that these alterations may differ depending on the specific HOX gene involved and the type of cancer being investigated. ${ }^{25,26}$ However, conditions under which it assumes either role remain to be elucidated. While it is possible that HOXA9 plays an important regulatory role in NPC, further research is required to determine specific mechanisms by which it impacts tumour progression of NPC.

\section{Conclusions}

Because HOXA9 levels are specifically elevated in NPC tissues and this is closely associated with NPC prognosis, this protein represents a promising potential novel biomarker for both diagnosis and prognosis, and may yet be proven to be a novel therapeutic target.

\section{Data Sharing Statement}

The datasets used and/or analyzed during the current study are available from the corresponding author on reasonable request.

\section{Ethical Approval}

All procedures performed in studies involving human participants were in accordance with the ethical standards of the institutional committee and with the 1964 Helsinki declaration and its later amendments or comparable ethical standards. The research was ratified by the Medical Ethics Committee of Shengjing Hospital of China Medical University. The patients and healthy controls were informed about the purpose of the study.

\section{Acknowledgment}

Thanks are due to Dabo ZHOU with technical assistance and valuable discussion.

\section{Funding}

This research was supported by the Projects of Shenyang Science and Technology Bureau (grant no. 20-205-4-029).

\section{Disclosure}

The authors declare that they have no conflicts of interest in this work.

\section{References}

1. Chua MLK, Wee JTS, Hui EP, et al. Nasopharyngeal carcinoma. Lancet. 2016;387(10022):1012-1024. doi:10.1016/S0140-6736(15) 00055-0

2. Chen W, Zheng R, Baade PD, et al. Cancer statistics in China, 2015. CA Cancer J Clin. 2016;66(2):115-132.

3. Chen W, Xia C, Zheng R, et al. Disparities by province, age, and sex in site-specific cancer burden attributable to 23 potentially modifiable risk factors in China: a comparative risk assessment. Lancet Glob Health. 2019;7(2):e257-e269.

4. Blanchard P, Lee A, Marguet S, et al. MAC-NPC Collaborative Group. Chemotherapy and radiotherapy in nasopharyngeal carcinoma: an update of the MAC-NPC meta-analysis. Lancet Oncol. 2015;16(6):645-655.

5. Yang L, Xia L, Wang Y, et al. Development and external validation of nomograms to predict the risk of skeletal metastasis at the time of diagnosis and skeletal metastasis-free survival in nasopharyngeal carcinoma. BMC Cancer. 2017;17(1):628.

6. Quinonez SC, Innis JW. Human HOX gene disorders. Mol Genet Metab. 2014;111(1):4-15.

7. Bhatlekar S, Fields JZ, Boman BM. HOX genes and their role in the development of human cancers. J Mol Med (Berl). 2014;92 (8):811-823.

8. Collins CT, Hess JL. Deregulation of the HOXA9/MEIS1 axis in acute leukemia. Curr Opin Hematol. 2016;23(4):354-361.

9. Janmaat VT, Liu H, da Silva RA, et al. HOXA9 mediates and marks premalignant compartment size expansion in colonic adenomas. Carcinogenesis. 2019;40(12):1514-1524.

10. Qin K, Tian G, Chen G, et al. miR-647 inhibits glioma cell proliferation, colony formation and invasion by regulating HOXA9. J Gene Med. 2020;22(3):e3153.

11. Wrangle J, Machida EO, Danilova L, et al. Functional identification of cancer-specific methylation of CDO1, HOXA9, and TAC1 for the diagnosis of lung cancer. Clin Cancer Res. 2014;20(7):1856-1864.

12. Chang SL, Chen TJ, Lee YE, et al. CDKN3 expression is an independent prognostic factor and associated with advanced tumor stage in nasopharyngeal carcinoma. Int J Med Sci. 2018;15(10):992-998.

13. Li J, Ye M, Zhou C. Expression Profile and Prognostic Values of HOXA Family Members in Laryngeal Squamous Cell Cancer. Front Oncol. 2020;10:368.

14. Ramos-Mejía V, Navarro-Montero O, Ayllón V, et al. HOXA9 promotes hematopoietic commitment of human embryonic stem cells. Blood. 2014;124(20):3065-3075.

15. Popovic R, Erfurth F, Zeleznik-le N. Transcriptional complexity of the HOXA9 locus. Blood Cells Mol Dis. 2008;40(2):156-159.

16. Collins CT, Hess JL. Role of HOXA9 in leukemia: dysregulation, cofactors and essential targets. Oncogene. 2016;35(9):1090-1098.

17. Pojo M, Gonçalves CS, Xavier-Magalhães A, et al. A transcriptomic signature mediated by HOXA9 promotes human glioblastoma initiation, aggressiveness and resistance to temozolomide. Oncotarget. 2015;6(10):7657-7674.

18. Costa BM, Smith JS, Chen Y, et al. Reversing HOXA9 oncogene activation by PI3K inhibition: epigenetic mechanism and prognostic significance in human glioblastoma. Cancer Res. 2010;70 (2):453-462.

19. Watanabe Y, Saito M, Saito K, et al. Upregulated HOXA9 expression is associated with lymph node metastasis in colorectal cancer. Oncol Lett. 2018;15(3):2756-2762.

20. Bhatlekar S, Ertel A, Gonye GE, et al. Gene expression signatures for HOXA4, HOXA9, and HOXD10 reveal alterations in transcriptional regulatory networks in colon cancer. J Cell Physiol. 2019;234 (8):13042-13056.

21. Hwang JA, Lee BB, Kim Y, et al. HOXA9 inhibits migration of lung cancer cells and its hypermethylation is associated with recurrence in non-small cell lung cancer. Mol Carcinog. 2015;54(Suppl 1):E72-80. 
22. Zhao Y, Zheng R, Chen J, et al. CircRNA CDR1as/miR-641/HOXA9 pathway regulated stemness contributes to cisplatin resistance in non-small cell lung cancer (NSCLC). Cancer Cell Int. 2020;20:289.

23. Bhatlekar S, Viswanathan V, Fields JZ, et al. Overexpression of HOXA4 and HOXA9 genes promotes self-renewal and contributes to colon cancer stem cell overpopulation. J Cell Physiol. 2018;233 (2):727-735.

24. Ju T, Jin H, Ying R, et al. Overexpression of NAC1 confers drug resistance via HOXA9 in colorectal carcinoma cells. Mol Med Rep. 2017;16(3):3194-3200.
25. Brotto DB, Siena ÁDD, de Barros II, et al. Contributions of HOX genes to cancer hallmarks: enrichment pathway analysis and review. Tumour Biol. 2020;42(5):1010428320918050.

26. Pai P, Sukumar S. HOX genes and the NF- $\mathrm{B}$ pathway: a convergence of developmental biology, inflammation and cancer biology. Biochim Biophys Acta Rev Cancer. 2020;1874(2):188450.

\section{Publish your work in this journal}

Cancer Management and Research is an international, peer-reviewed open access journal focusing on cancer research and the optimal use of preventative and integrated treatment interventions to achieve improved outcomes, enhanced survival and quality of life for the cancer patient.
The manuscript management system is completely online and includes a very quick and fair peer-review system, which is all easy to use. Visit http://www.dovepress.com/testimonials.php to read real quotes from published authors. 